\title{
RETRACTED ARTICLE: Artificial neural network for prediction of mixed response variables: simulation and application
}

M. Sedehi • Y. Mehrabi • A. Kazemnejad •

V. Joharimajd $\cdot$ F. Hadaegh

Received: 25 February 2010/Accepted: 28 July 2010/Published online: 14 August 2010

(C) Springer-Verlag London Limited 2010

This article has been removed following an investigation into plagiarism, and with the agreement of the authors.

M. Sedehi · A. Kazemnejad

Faculty of Medicine, Tarbiat Modares University, Tehran, Iran

Y. Mehrabi $(\square)$

Department of Epidemiology, School of Public Health,

Shahid Beheshti University of Medical Sciences,

Evin, Tehran, Iran

e-mail: mehrabi@sbmu.ac.ir

V. Joharimajd

Faculty of Electricity Engineering, Tarbiat Modares University,

Tehran, Iran

F. Hadaegh

Prevention of Metabolic Disorders Research Center,

Research Institute for Endocrine Sciences, Shahid Beheshti

University of Medical Sciences, Tehran, Iran 